\title{
WORLD METROLOGY DAY 2015: MEASUREMENTS AND LIGHT METROLOGY FOR LIGHT AND LIGHT FOR METROLOGY. MESSAGE FROM THE BIPM DIRECTOR
}

\section{Martin Milton}

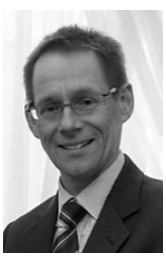

This year, World Metrology Day is aligned with the International Year of Light and Light-based Technologies proclaimed by the General Assembly of the UN and organized by UNESCO. Events in 2015 will celebrate the central role of light to life, whether as a source of energy, as the basis for photonic technologies, or as being a source of wonder and excitement.

Metrology plays a central role in enabling the application of light-based technologies, for example:

- as new forms of efficient lighting are developed, new measurements are needed to quantify their efficiency and the influence they have on the appearance of objects;

- decisions to invest in solar photovoltaic technologies are based on accurate data for their efficiency and lifetime;

- direct measurements of the sun made from satellites are essential to underpin our understanding of solar irradiance and its contribution to climate change.

In turn, light is at the heart of many of the most important new elements of leading-edge measurement technologies. For many decades, the most accurate length measurements have depended on highly-stable lasers, and many highly-sensitive chemical measurements use tunable lasers that can sense individual transitions in target molecules. The capabilities of stable lasers now extend to providing the most accurate "optical clocks" that depend on the light emitted from single atoms that have been slowed down and trapped by laser beams.

I hope that the celebration of World Metrology Day on 20th May 2015 will trigger new liaisons between the metrology community and those who work to develop and exploit light-based technologies. It is the opportunity to show that just as life depends on light, so the safe, efficient, and effective supply of light depends on measurement. 